\title{
Comparison of parturient - controlled remifentanil with epidural bupivacain and sufentanil for labour analgesia: Randomised controlled trial
}

\author{
Petr Stourac ${ }^{\mathrm{a}, \mathrm{c}, \mathrm{d}}$, Hana Suchomelova ${ }^{\mathrm{a}, \mathrm{d}}$, Marta Stodulkova ${ }^{\mathrm{d}}$, Martin Huser ${ }^{\mathrm{b}, \mathrm{d}}$, Ivo Krikava ${ }^{\mathrm{a}, \mathrm{c}, \mathrm{d}}$, Petr Janku ${ }^{\mathrm{b}, \mathrm{d}}$, Olga Haklovac, \\ Lubomir Hakl ${ }^{c}$, Roman Stoudek ${ }^{\mathrm{a}, \mathrm{d}}$, Roman Gal ${ }^{\mathrm{a}, \mathrm{d}}$, Pavel Sevcik ${ }^{\mathrm{a}, \mathrm{c}, \mathrm{d}}$
}

\begin{abstract}
Introduction. Epidural analgesia (EA) has significant contraindications including coagulation disorders and parturient refusal. One alternative is intravenous self-administered analgesia using the ultra short-acting opioid remifentanil (rPCA). We compared the efficiency and safety of standard epidural analgesia with parturient-controlled intravenous analgesia using remifentanil as well as personal satisfaction.
\end{abstract}

Materials and Methods. We enrolled twelve ASA I classified women with singleton pregnancy who delivered vaginally in the period 3/2010-5/2010 and who received rPCA $(n=12)$ in standard analgesic protocol: $20 \mu \mathrm{g}$ boluses using PCA pump with a lockout interval of $3 \mathrm{~min}$. The control group consisted of 12 pregnant women who received EA ( $n=12)$ : $0.125 \%$ bupivacaine with sufentanil $0.5 \mu \mathrm{g} / \mathrm{mL}$ in top-up boluses every hour until delivery. Data were acquired from standard Acute Pain Service (APS) form and patient medical records (demographic, labour course parameters), Visual Analogue Scale (VAS), Bromage Scale (BS) and adverse effects of analgesia.

Results. There were no demographic or labour course parameter differences between groups $(P>0.05)$. The differences in VAS decrease $(P=0.056)$ and parturient satisfaction $(P=0.24)$ during the whole analgesia administration were statistically insignificant. The main limitation of the study was small sample and enrolment of healthy singleton pregnant women only.

Conclusion. Remifentanil use in obstetric analgesia is a viable alternative to EA, especially in cases of EA contraindications and parturient disapproval.

Key words: obstetric analgesia, epidural analgesia, parturient-controlled intravenous analgesia, remifentanil

Received: January 11, 2012; Accepted with revision: July 9, 2012; Available online: October 31, 2012

http://dx.doi.org/10.5507/bp.2012.073

${ }^{a}$ Department of Anaesthesiology and Intensive Care Medicine, Faculty Hospital Brno, Czech Republic

${ }^{b}$ Department of Obstetrics and Gynecology, Faculty Hospital Brno

'Department of Pain Control, Faculty Hospital Brno

${ }^{d}$ Faculty of Medicine, Masaryk University, Brno

Corresponding author:Petr Stourac, e-mail: petr.stourac@gmail.com

\section{INTRODUCTION}

Pain perception during labour is very individual. Many women, despite being well- prepared, are shocked by the intensity of the acute pain. Labour pain management decreases the excessive stress which could lead to undesired pathological somatic and psychological reactions ${ }^{1-4}$.

Lumbar epidural analgesia offers a safe and effective method for pain relief during labour. While there are a large number of relative contraindications, there are a few absolute contraindications to neuroaxial analgesia. These include patient refusal, overt maternal coagulopathy, infection at the needle site, and maternal hemodynamic instability $^{5}$.

Therefore, there is a need find an effective alternative to epidural analgesia, which would have an easier and lower-risk administration procedure, fast effect onset and minimal side effects on the parturient and foetus. One alternative is intravenous parturient-controlled analgesia using remifentanil (rPCA) $\left(\right.$ ref. $\left.^{6}\right)$.
Remifentanil is a relatively new, ultra-short acting synthetic opioid with fast onset and which is rapidly metabolised by non-specific plasma and tissue esterases ${ }^{7}$. Its estimated half-life is $1.3 \mathrm{~min}$, and prolonged administration does not appear to cause accumulation of this drug ${ }^{8,9}$.

The aim of the present study was to compare the analgesic efficacy of parturient controlled intravenous remifentanil administration with epidural analgesia during first stage of labour with regard to maternal and early neonatal side-effects. We also aimed to confirm this clinically very simple method (rigid dosage regimen of remifentanil) of patient-controlled administration of remifentanil.

\section{MATERIAL AND METHODS}

We obtained the consent of the local ethics committee to this prospective, randomised trial, at the outset. The study lasted from March 2010 to May 2010. Inclusion criteria $(\mathrm{N}=81)$ were : no comorbidities (ASA I), singleton 
head-down full term pregnancy, spontaneous or induced labour. The informed consent of the women was obtained before administration of analgesia. In the case of refusal to sign informed consent $(\mathrm{N}=53)$, the data were excluded from statistical evaluation. Women who had asked for obstetric analgesia and met the inclusion criteria were offered the PCA using remifentanil (randomisation by the parturient). The data of the parturients whose pregnancies were terminated by Caesarean Section were excluded from statistical evaluation.

\section{Acute Pain Service Form}

The data were recorded using the standard Acute Pain Service (APS) form used in our hospital for peripartal monitoring including the basic information about the parturient, coagulation parameters, gynaecological anamnesis, history of headache, timing (regular contractions initiation time, time of analgesia request and its administration and the respective results of vaginal examination), delivery details (pregnancy termination method, Apgar score and umbilical blood $\mathrm{pH}$ ), medication including prostaglandins, oxytocine or spasmolytics, analgesia details (method of epidural space access, concentration and amount of the analgetics given, administration method and anaesthesiological complications). The APS form also contained a detailed labour analgesia monitoring table where blood pressure, heart rate, amount of analgetics given, administration of other systemic analgetics, VAS pain score and Bromage score were recorded regularly: immediately before the first administration of analgesia, every $30 \mathrm{~min}$ up to the delivery and $2 \mathrm{~h}$ and $24 \mathrm{~h}$ after the delivery. Visual Analogue Scale (VAS) objectifies the parturient's pain perception on a special scale from 0 (no pain) to 10 (the worst imaginable pain). Bromage score (BS) $\left(\right.$ ref. $\left.{ }^{10}\right)$ reflects the level of motor block of lower extremities after neuraxial analgesia administration (I - free movement of legs and feet, II - just able to flex knees with free movement of feet, III - unable to flex knees, but with free movement of feet, IV - unable to move legs or feet). After the delivery, the Apgar score was assessed by perinatologist and the umbilical cord blood sample was taken for $\mathrm{pH}$ analysis. Level of the parturient satisfaction and their comments on the analgesia provided analgesia evaluation, additional to the information obtained by VAS pain score analysis. The level of the parturient satisfaction was assessed by mean percentage score ( $100 \%$ - fully satisfied, $75 \%$ - somewhat satisfied, $25 \%$ - somewhat dissatisfied, $0 \%$ - fully dissatisfied) for both methods.

\section{Epidural administration}

The parturients undergoing EA had an epidural catheter inserted into the epidural space by an anaesthesiologist. The dosage regimen of bupivacaine and sufentanil in the EA group was rigidly set to induction dose of $12.5 \mathrm{mg}$ of bupivacaine and $5 \mu \mathrm{g}$ of sufentanil in $10 \mathrm{~mL}$ of normal saline; top-up boluses of half-size dose were repeated in 60-90 min intervals. The epidural catheter was extracted after the delivery, at least two hours before the parturient's transport to post-natal care ward.

\section{Remifentanil administration}

The parturients were closely informed by an anaesthesiologist of this method and its possible side effects and instructed in the PCA device operation. After the parturient's consent, her peripheral vein was cannulated and infusion of normal saline up to $2 \mathrm{~mL} / \mathrm{kg} / \mathrm{h}$ was started. The PCA device was connected to the same cannula. Remifentanil (Ultiva, Glaxo-Smith-Kline, Great Britain) was then administered via the PCA device (Technic 1, AMV Technics, Czech Republic) from a $50 \mathrm{~mL}$ syringe in a concentration of $20 \mu \mathrm{g} / \mathrm{mL}$. On demand, the parturient received an intravenous bolus of $20 \mu \mathrm{g}(1 \mathrm{~mL})$ of remifentanil. Lock-out interval was set to $3 \mathrm{~min}$. The significant analgesic effect was set to a minimal VAS score decrease of 2 , based on existing evidence ${ }^{6}$. In case of inadequate analgesic VAS decrease $(<2)$, it was possible for the anaesthesiologist to increase the dose in $10 \mu \mathrm{g}$ steps.

\section{Monitoring}

The parturient was observed by a healthcare worker continously in the delivery room and her blood pressure, VAS pain score, amount of analgetic administered and sedation level were recorded every $30 \mathrm{~min}$. If any signs of sedation (drowsiness), dizzines, muscle rigidity or bradypnoe (breaths under 10 per min) were observed, the lockout interval could be extended by 1 minute.

\section{Side effects}

Side effects of remifentanil, such as respiratory depression (breaths under 10 per minute), bradycardia $(<50$ bpm), hypotension, muscle rigidity, nausea and vomiting were recorded thoroughly. Hypotension criteria were set as a systolic blood pressure decrease of $25 \%$ or more from the baseline blood pressure (i.e. the blood pressure recorded before initiation of analgesia).

\section{Statistical methods}

According to average number of labours per month in the local Obstetrics Department we aimed to enroll in both groups 30 parturients with the power set at $>80 \%$. $P$ values less then 0.05 were considered significant.

The data were analysed using the software Statistica 7.0 (StatSoft, Czech Republic). The data were summarised as means, median, standard deviation and confidence interval). The Wilcoxon Matched Pairs Test was used for VAS pain score decrease analysis. The MannWhitney U-Test was used for comparison of differencies between both groups. The level of the parturients' satisfaction was assessed by mean percentage score for both methods used.

\section{RESULTS}

During the study period, 28 parturients met the requirements to take part in this prospective randomised trial. This low count was caused by high parturient refusal to participate in the study $(\mathrm{N}=53)$ despite agreement with labour analgesia. We are aware of the decreased power 
with the lower sample size; nevertheless the $95 \%$ confidence interval for endpoint estimate in the groups showed clinically non-significant results within its whole range which supports our findings from the statistical testing. Therefore we decide to terminate the enrolment. Four pregnancies were terminated by Caesarean Section ( 2 of them due to labour progress stagnancy, 2 because of a pathological cardiotocography (CTG) record ( 1 in each branch)).

\section{Parturient study flow is shown in Fig. 1.}

The following analysis is based only on the data from the observation of 24 women who delivered vaginally. Parturient characteristics, labour course and neonatal parameters are shown in Table1. Both groups characteristic, labour and VAS course and neonatal parameters differencies were found statistically insignificant (Table 2). The only statistically significant difference between the two studied groups was the cervical dilatation at the time of the analgesia initiation $(P=0.013)$ without clinical significance.

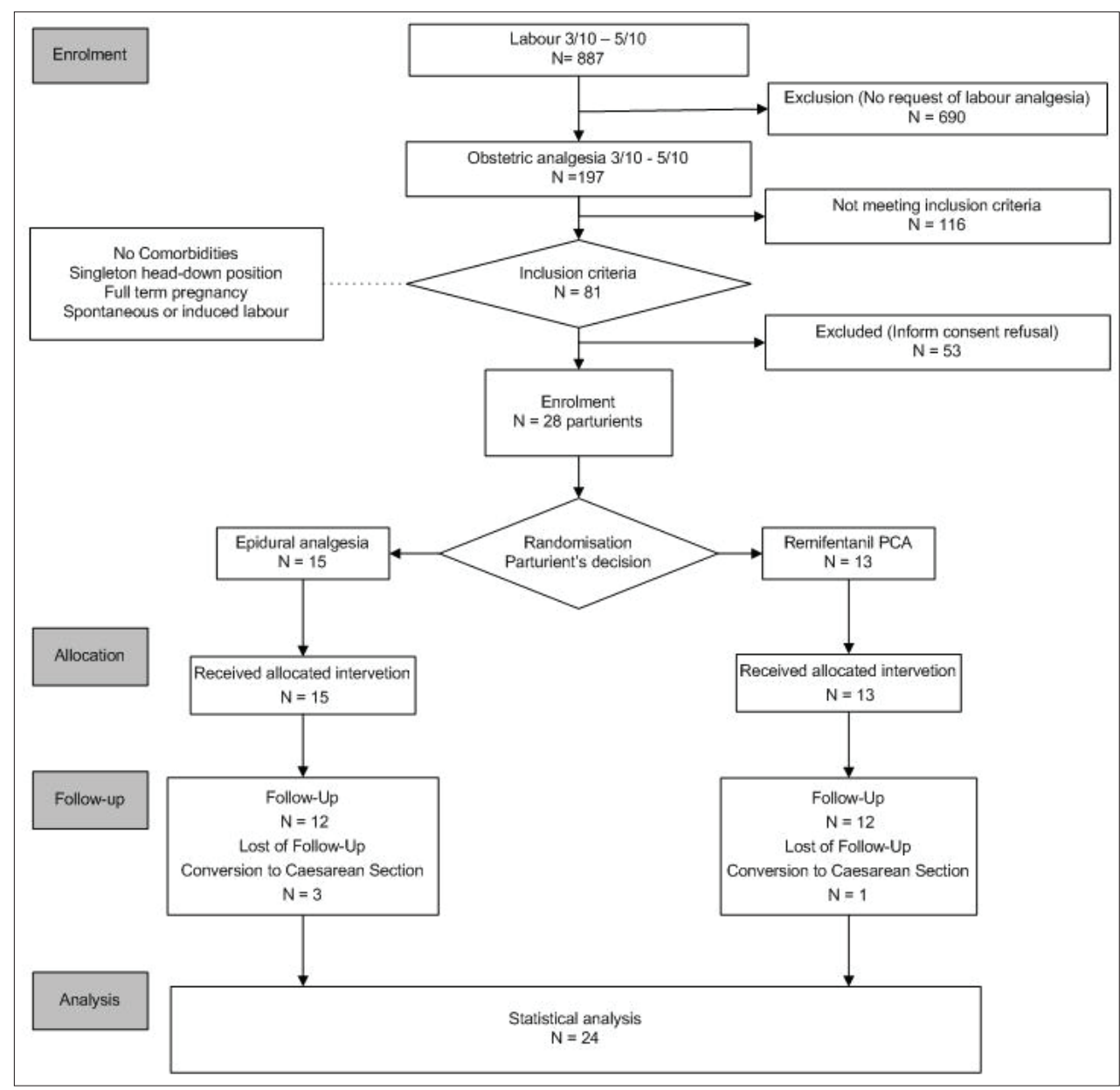

Fig. 1. Study patient flow.

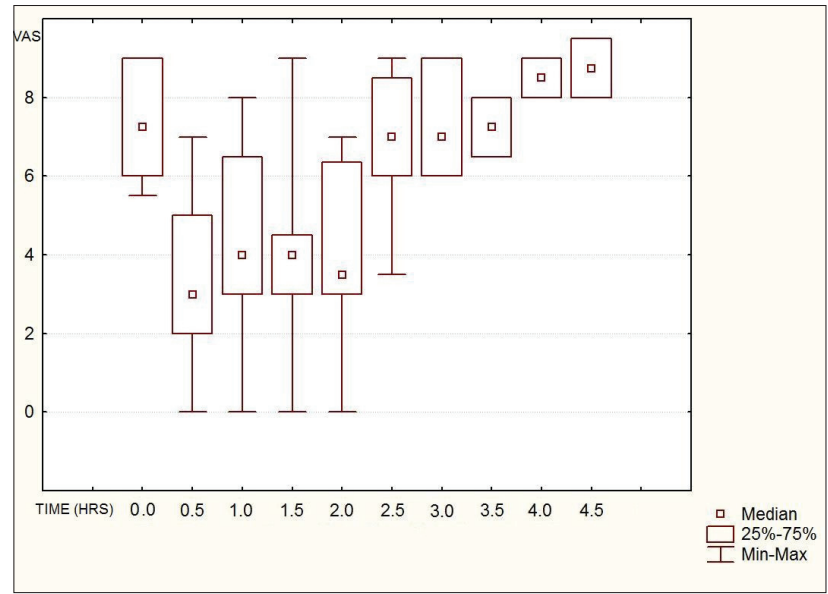

Fig. 2. Visual Analogue Scale (VAS) Pain Score during Application of Epidural Analgesia.

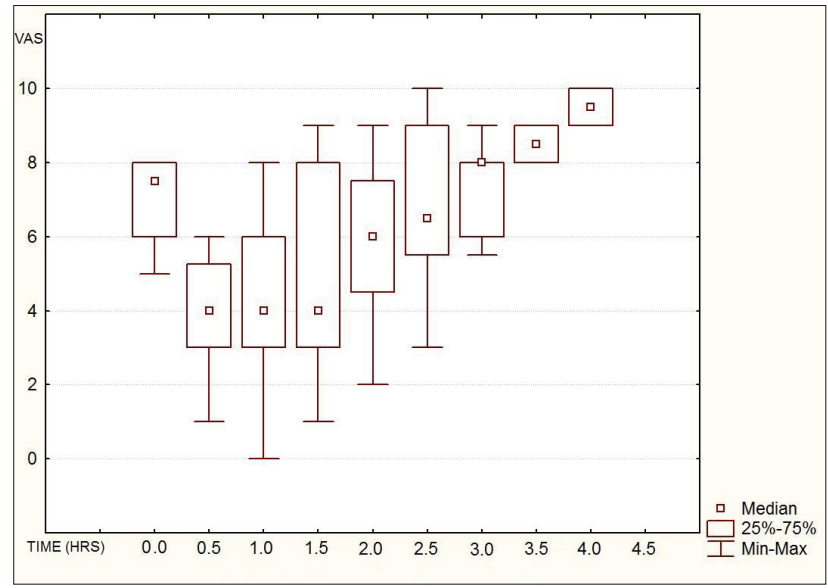

Fig. 3. Visual Analogue Scale (VAS) Pain Score during Application of Remifentanil Parturient-Controlled Analgesia. 
Table 1. Characteristics of the Parturients Completing the Study.

\begin{tabular}{|c|c|c|c|c|c|c|c|c|c|c|c|c|c|c|c|c|}
\hline \multirow{2}{*}{ No. } & \multirow{2}{*}{ Analgesia } & \multirow{2}{*}{$\begin{array}{c}\text { Age } \\
\text { (years) }\end{array}$} & \multirow{2}{*}{$\begin{array}{c}\text { Gravidity } \\
\text { duration } \\
\text { (weeks + } \\
\text { days) }\end{array}$} & \multirow{2}{*}{ Parity } & \multirow{2}{*}{$\begin{array}{c}\text { Labour } \\
\text { induc- } \\
\text { tion }\end{array}$} & \multirow{2}{*}{$\begin{array}{l}\text { Height } \\
(\mathrm{cm})\end{array}$} & \multirow{2}{*}{$\begin{array}{l}\text { Weight } \\
(\mathrm{kg})\end{array}$} & \multirow{2}{*}{$\begin{array}{c}\text { BMI } \\
\left(\mathrm{m}^{2} / \mathrm{kg}\right)\end{array}$} & \multicolumn{3}{|c|}{$\begin{array}{l}\text { Duration of labour } \\
\text { stages (min) }\end{array}$} & \multirow{2}{*}{$\begin{array}{c}\text { Analgesia } \\
\text { Duration } \\
(\mathrm{min})\end{array}$} & \multicolumn{3}{|c|}{ Apgar score } & \multirow{2}{*}{$\mathrm{pH}$} \\
\hline & & & & & & & & & $1 \mathrm{st}$ & $2 \mathrm{nd}$ & $3 \mathrm{rd}$ & & $\begin{array}{c}1 \mathrm{st} \\
\min \end{array}$ & $\begin{array}{l}5 \text { th } \\
\min \end{array}$ & $\begin{array}{l}10 \text { th } \\
\min \end{array}$ & \\
\hline 1 & EA & 32 & $40+0$ & II & $\mathrm{W} / \mathrm{O}$ & 171 & 101 & 34.54 & 260 & 10 & 45 & 122 & 9 & 10 & 10 & - \\
\hline 2 & EA & 28 & $37+3$ & I & $\mathrm{W} / \mathrm{O}$ & 165 & 96 & 35.26 & 340 & 0 & 2 & 325 & 9 & 10 & 10 & 7.32 \\
\hline 3 & EA & 29 & $41+0$ & I & YES & 168 & 87 & 30.82 & 150 & 50 & 25 & 150 & 9 & 10 & 10 & 7.31 \\
\hline 4 & EA & 30 & $41+2$ & I & YES & 167 & 78 & 27.97 & 260 & 5 & 10 & 190 & 9 & 9 & 9 & - \\
\hline 5 & EA & 31 & $39+4$ & II & YES & 170 & 93 & 32.18 & 160 & 10 & 10 & 60 & 7 & 8 & 9 & 7.21 \\
\hline 6 & EA & 28 & $39+0$ & I & YES & 158 & 54 & 21.63 & 135 & 5 & 10 & 100 & 10 & 10 & 10 & 7.4 \\
\hline 7 & EA & 30 & $40+4$ & I & YES & 168 & 73 & 25.86 & 265 & 10 & 35 & 220 & 3 & 6 & 8 & 6.99 \\
\hline 8 & EA & 24 & $39+4$ & I & $\mathrm{W} / \mathrm{O}$ & 173 & 82 & 27.4 & 335 & 10 & 10 & 185 & 9 & 10 & 10 & 7.18 \\
\hline 9 & EA & 32 & $40+2$ & I & YES & 171 & 76 & 25.99 & 220 & 15 & 15 & 225 & 9 & 9 & 10 & - \\
\hline 10 & EA & 29 & $39+3$ & I & YES & 163 & 83 & 31.24 & 270 & 30 & 10 & 150 & 9 & 10 & 10 & 7.33 \\
\hline 11 & EA & 30 & $40+3$ & I & $\mathrm{W} / \mathrm{O}$ & 170 & 124 & 42.91 & 365 & 10 & 10 & 300 & 9 & 10 & 10 & - \\
\hline \multirow[t]{4}{*}{12} & EA & 30 & $41+1$ & I & YES & 175 & 83 & 27.1 & 200 & 10 & 10 & 105 & 10 & 10 & 10 & 7.4 \\
\hline & Mean & 29.4 & $40+0$ & & & 168.3 & 85.83 & 30.24 & 246.7 & 13.75 & 16 & 177.67 & 8.5 & 9.3 & 9.67 & 7.27 \\
\hline & $\mathrm{SD}$ & 2.05 & $1+0$ & & & 4.42 & 16.75 & 5.35 & 76.3 & 13.51 & 12.54 & 80.17 & 1.88 & 1.23 & 0.65 & 0.137 \\
\hline & Median & 30 & $40+1$ & & & 169 & 83 & 29.395 & 260 & 10 & 10 & 167.5 & 9 & 10 & 10 & 7.315 \\
\hline 13 & rPCA & 24 & $41+5$ & I & YES & 165 & 80 & 29.38 & 340 & 15 & 45 & 273 & 7 & 8 & 8 & - \\
\hline 14 & rPCA & 23 & $37+6$ & I & YES & 165 & 74 & 27.18 & 165 & 10 & 10 & 65 & 8 & 10 & 10 & 7.14 \\
\hline 15 & rPCA & 31 & $39+2$ & I & $\mathrm{W} / \mathrm{O}$ & 172 & 70 & 23.66 & 260 & 10 & 25 & 160 & 9 & 10 & 10 & - \\
\hline 16 & rPCA & 29 & $38+4$ & III & YES & 162 & 69 & 26.29 & 335 & 5 & 5 & 205 & 9 & 10 & 10 & 7.31 \\
\hline 17 & rPCA & 32 & $40+2$ & II & YES & 168 & 75 & 26.57 & 150 & 15 & 25 & 50 & 8 & 9 & 9 & 7.32 \\
\hline 18 & rPCA & 29 & $38+1$ & II & YES & 168 & 89 & 31.53 & 355 & 5 & 5 & 170 & 10 & 10 & 10 & 7.06 \\
\hline 19 & $\mathrm{rPCA}$ & 32 & $39+2$ & II & YES & 170 & 77 & 26.64 & 235 & 5 & 5 & 90 & 9 & 9 & 10 & 7.4 \\
\hline 20 & rPCA & 29 & $40+2$ & I & $\mathrm{W} / \mathrm{O}$ & 165 & 86 & 31.59 & 240 & 10 & 15 & 195 & 9 & 10 & 10 & - \\
\hline 21 & rPCA & 27 & $41+4$ & I & YES & 165 & 133 & 48.85 & 250 & 10 & 15 & 200 & 9 & 9 & 10 & 7.2 \\
\hline 22 & rPCA & 25 & $39+1$ & I & YES & 164 & 81 & 30.12 & 315 & 40 & 10 & 290 & 9 & 10 & 10 & - \\
\hline 23 & rPCA & 29 & $40+3$ & I & YES & 176 & 98 & 31.64 & 230 & 10 & 10 & 90 & 9 & 9 & 9 & 7.31 \\
\hline \multirow[t]{4}{*}{24} & rPCA & 25 & $36+6$ & I & YES & 164 & 76 & 28.26 & 255 & 0 & 15 & 165 & 9 & 10 & 10 & 7.33 \\
\hline & Mean & 27.9 & $39+3$ & & & 167 & 84 & 30.14 & 260.8 & 11.25 & 15.42 & 162.75 & 8.75 & 9.5 & 9.67 & 7.26 \\
\hline & $\mathrm{SD}$ & 2.95 & $1+3$ & & & 3.83 & 16.75 & 6.13 & 65.5 & 10.01 & 11.57 & 77.15 & 0.75 & 0.67 & 0.65 & 0.107 \\
\hline & Median & 29 & $39+1.5$ & & & 165 & 78.5 & 28.82 & 252.5 & 10 & 12.5 & 167.5 & 9 & 9 & 10 & 7.31 \\
\hline
\end{tabular}

BMI - body mass index; EA - epidural analgesia; rPCA - remifentanil parturient controlled analgesia;

The rPCA rigid administration scheme (20 $\mu \mathrm{g}$ bolus with lock-out interval $3 \mathrm{~min}$ ) was used for all parturients. Three parturients required a further dose increase to 30 $\mu \mathrm{g}$ and $40 \mu \mathrm{g}$ due to insufficient analgesic effect.

Comparison of VAS decrease during labour is given in Table 2. There is no significant difference between the groups. A pain score of $\leq 3$ (bearable pain) was recorded by $67 \%$ parturients in the EA group and by $42 \%$ parturients in the rPCA group. Statistically significant difference $(P=0.002)$ between the baseline pain scores and the lowest recorded pain scores was found for both analgesic groups. Progression of VAS in the EA group during labour is shown in Fig. 2. Progression of VAS score in the rPCA group is shown in the Fig. 3. The differences between the pain scores recorded during EA and those recorded during rPCA administration were not statistically significant $(P>0.05)$ throughout the entire administration period.

\section{Satisfaction}

Level of the parturients' satisfaction with analgesia was $88 \%(0-100 \%)$ in the EA group and $85 \%(75-100 \%)$ in the rPCA group $(P=0.24)$. Complete dissatisfaction was expressed by one woman in EA group, the most of
Table 2. Comparison of Parturients Characteristics, Neonatal, Labour and VAS Course Parameters.

\begin{tabular}{lrrl}
\hline & EA & rPCA & P \\
& Mean & Mean & \\
\hline Age (years) & 29.42 & 27.92 & NS \\
Gestures (days) & 279.83 & 276.16 & NS \\
Labor induction & 0.66 & 0.83 & NS \\
Height $(\mathrm{cm})$ & 168.25 & 167.00 & NS \\
Weight $(\mathrm{kg})$ & 85.83 & 84.00 & NS \\
BMI $(\mathrm{m} 2 / \mathrm{kg})$ & 30.24 & 30.14 & $\mathrm{NS}$ \\
1st stage $(\min )$ & 246.67 & 260.83 & $\mathrm{NS}$ \\
2nd stage $(\mathrm{min})$ & 13.75 & 11.25 & $\mathrm{NS}$ \\
3rd stage $(\mathrm{min})$ & 16.00 & 15.42 & $\mathrm{NS}$ \\
pH & 7.27 & 7.26 & $\mathrm{NS}$ \\
\hline VAS 0 h $(\mathrm{N}=24)$ & 7.33 & 7.04 & $\mathrm{NS}$ \\
VAS 0.5 h $(\mathrm{N}=24)$ & 3.29 & 4.13 & $\mathrm{NS}$ \\
VAS 1.0 $\mathrm{h}(\mathrm{N}=22)$ & 4.14 & 4.64 & $\mathrm{NS}$ \\
VAS 1.5 $\mathrm{h}(\mathrm{N}=19)$ & 4.05 & 5.33 & $\mathrm{NS}$ \\
VAS 2.0 $\mathrm{h}(\mathrm{N}=16)$ & 4.09 & 5.88 & $\mathrm{NS}$ \\
\hline Satisfaction $(\%)$ & 88 & 85 & $\mathrm{NS}$ \\
\hline
\end{tabular}

NS (Not Significant $P>0.05$ ); BMI (Body Mass Index); VAS (Visual Analogue Score) 
parturients were fully satisfied (9 women in EA group, 5 women in rPCA group).

\section{Complications}

Hypotension occurred in one parturient from the rPCA group two hours after delivery (i.e. over two hours after the last dose of remifentanil was administered), and it was more likely associated with a greater blood loss during the delivery than the analgesia itself. Bradycardia did not occur in any of the parturients.

All the parturients with rPCA experienced a certain level of drowsiness and dizziness (100\%). Advantageously, all the parturients with rPCA also experienced at least a temporary anxiolysis. Muscle rigidity was not observed in any of the parturients. Nausea and vomiting occurred in two (17\%) parturients before the rPCA was initiated, and persisted during the analgesia.

The most common complications of EA were repetitive puncture in $33 \%$ of cases, and tingling without paresthesia in $17 \%$ of cases. In one case $(8 \%)$, blood appeared in the inserted epidural catheter. Bromage score did not exceed its grade I in any of the parturients with EA.

\section{DISCUSSION}

The difference in the analgetic efficiency of EA and rPCA in the used dosage regimen [bupivacaine $12.5 \mathrm{mg}$ and sufentanil $5 \mu \mathrm{g}$ in $10 \mathrm{~mL}$ for EA and $20 \mu \mathrm{g}$ of remifentanil for rPCA] during the whole analgesia administration period was statistically insignificant. However, EA is temporarily able to cause a greater pain score decrement, which was not found for the rPCA group [the maximum pain score decrement from the baseline during the analgesia administration was 5.25 (3-6) in the EA group and only 3.75 (1-5) in the rPCA group]. Pain may increase with the progression of labour as a result of sensitization $^{11}$. For this reason, the baseline pain score comparison with the pain scores recorded during the analgesia administration (i.e. later) has only limited significance. Another fact is that VAS pain score assessment always carries a significant subjective factor of pain perception, hence the recorded pain scores always have more or less limited significance.

Three parturients required a further dose increase due to an insufficient analgesic effect, but only one of these women experienced further pain relief. Two other women experienced more drowsiness than any significant pain score decrement.

Both types of analgesia appear to be equally safe for the neonates. An Apgar score below 8 for the $1^{\text {st }}$ minute or umbilical blood $\mathrm{pH}$ below 7.1 was recorded in two cases in the EA group. In one of these cases forceps was used due to the labour stagnation and CTG decelerations in the second stage of labour (Apgar score was 7, 8, 9 and the umbilical blood $\mathrm{pH}$ was 7.21), the second labour terminated spontaneously with CTG decelerations (Apgar score was 3, 6, 8 and umbilical blood $\mathrm{pH}$ was 6.99). In the rPCA group, these parameters were also recorded in two neonates. Both of these labours terminated spontane- ously, with second stage stagnation and CTG decelerations (Apgar score was 7, 8, 8 and umbilical blood $\mathrm{pH}$ was 7.14, resp. 8, 9, 9 and 7.06). CTG decelerations observed in the rest were the same in both analgesia groups and corresponded to normal CTG records of parturients with no analgesia. The CTG records of the three parturients requiring higher doses of remifentanil showed no changes related to the dose increase.

The level of satisfaction with both of the analgesia methods was approximately the same: $88 \%$ (0-100\%) in the EA group and $85 \%(75-100 \%)$ in the rPCA group. The most common complaint was insufficient analgetic effect, especially in the second stage of the labour. Main positive comments on the rPCA were epidural catheter insertion avoidance and the possibility of remifentanil selfadministration according to the individual needs. This led to absence of dissatisfied parturients given rPCA despite the smaller pain reduction.

When we were designing the study, there were no published comparative studies on remifentanil and epidural labour analgesia. Nevertheless, the maternal and neonatal effects of remifentanil were described. The feasibility and safety were proven and the regimen of accurate dosage was found. As the study progressed, three similar studies emerged. Volmanen et al. ${ }^{12}$ used higher doses of remifentanil and shorter lock-out interval. The PCA dose of remifentanil was given over $1 \mathrm{~min}$ with a lockout time of $1 \mathrm{~min}$. The dose was increased starting from a bolus of 0.1 $\mu \mathrm{g} / \mathrm{kg}$ and following a dose escalation scheme up until the individual-effective dose was reached. Sedation and low haemoglobin oxygen saturation were found more often during remifentanil analgesia. Foetal heart rate tracing abnormalities were as common in both groups. However, there was no difference in the pain relief scores between the treatments. The observation period was limited to the first hour of treatment. El-Kerdawy et al. ${ }^{13}$ demonstrated a significant decrease in VAS score in the first hour after administration of analgesia to 30 preeclamptic patients (randomly assigned to two equal groups- EA and rPCA) using different regimen with background infusion. PCA remifentanil infusion administered until the time of delivery produced no observable maternal, foetal or neonatal side effects. VAS pain scores were reported at only three points: a baseline scores before starting analgesia, $1 \mathrm{~h}$ after starting treatment, and after delivery. The investigation of Douma et al. ${ }^{14}$ on a group of 20 patients $(\mathrm{EA}=10, \mathrm{rPCA}=10)$ showed a distinct outcome: pain relief in labour with epidural ropivacaine/sufentanil was more effective than intravenous remifentanil patient-controlled analgesia.

The main limitation of the study was the small parturient sample although the $95 \%$ CI of endpoint estimate in the groups showed clinically non-significant results within their whole range which supports our findings from the statistical testing.

The other fact is that size of our study group is similar to the studies mentioned above, especially when our inclusion criteria are applied. For example, the newest study of Tveit et al. $(E A=20, r P C A=17)$ represents comparable results on a slightly wider group of parturients. However, 
the number of patients matching our inclusion criteria is almost the same $(\mathrm{EA}=13, \mathrm{rPCA}=12)$. Therefore we suggest that a too tight inclusion criteria might be another limitation of our study.

\section{CONCLUSION}

Remifentanil parturient-controlled intravenous analgesia and epidural analgesia provided effective analgesia with high parturient's satisfaction scores and clinically good neonatal outcomes. The data support the clinical use of rPCA as an alternative to standard epidural analgesia.

\section{CONFLICT OF INTEREST STATEMENT}

The authors state that there are no conflicts of interest regarding the publication of this article.

\section{REFERENCES}

1. Melzack R, Kinch RA, Dobkin P, Lebrun M, Taenzer P. Severity of labour pain: influence of physical as well as psychological variables. Can Med Assoc J 1984;130:579-84.

2. Melzack R, Taenzer $P$, Feldman $P$, Kinch RA. Labour is still painful after prepared childbirth training. Can Med Assoc J 1981;125:357-63.

3. Pařízek A. Porodní bolest. In: Rokyta R, Kršiak M, Kozák J, editors Bolest: monografie algeziologie. Praha; Tigis, 2006.p.453,684.
4. Pařízek A. Porodnická analgezie a anestezie. Praha; Grada Publishing, 2002: p.149-54, 257-307, 535.

5. Birnbach DJ, Browne IM. Anesthesia for Obstetrics. In: Miller RD Eriksson LI, Fleisher LA, Wiener-Kronish JP, Young WL. Miller's Anesthesia. Philadelphia; Churchill Livingstone Elsevier, 2010.p.22135 .

6. Blair JM, Hill DA, Fee JPH. Patient-controlled analgesia for labour using remifentanil: a feasibility study. BJA 2001;87(3):415-20.

7. Michelsen LG, Hug CC. The pharmacokinetics of remifentanil. J Clin Anesth 1996;8:679-82.

8. Glass PSA, Hardman D, Kamiyama Y, Timothy JQ, Marton G, Donn $\mathrm{KH}$, Grosse CM, Hermann D. Preliminary pharmacokinetics and pharmacodynamics of an ultra-short acting opiod: Remifentanil. Anesth Analg 1993;77:1031-40.

9. Kan RE, Hughes SC, Rosen MA, Kessin C, Preston PG, Lobo EP. Intravenous remifentanil : Placental transfer, maternal and neonatal effects . Anesthesiology 1998;88(6):1467-74.

10. Bromage PR: Mechanism of action. In: Bromage PR (Ed). Epidural Analgesia. Philadelphia;WB Saunders, 1978.p.144.

11. Pan PH, Eisenach JC. The Pain of Childbirth and Its Effect on the Mother and the Fetus. In: Chestnut DH, Polley LS, Tsen LC, Wong CA. Chestnut's Obstetric Anestesia: Principles and Practice. Philadelphia; Mosby Elsevier, 2009.p.392.

12. Volmanen P, Sarvela J, Akural El, Raudaskoski T, Korttila K, Alahuhta S. Intravenous remifentanil vs. epidural levobupivacaine with fentanyl for pain relief in early labour: a randomised, controlled, doubleblinded study. Act Anest Scand 2008;52(2):249-55.

13. El-Kerdawy $\mathrm{H}$, Farouk A. labour analgesia in preeclampsia: remifentanil patient controlled intravenous analgesia versus epidural analgesia. M E J Anesth 2010;20(4):539-46.

14. Douma MR, Middeldorp JM, Verwey RA, Dahan A, Stienstra R. A randomised comparison of intravenous remifentanil patient-controlled analgesia with epidural ropivacaine/sufentanil during labour. Int J Obstet Anesth 2011;20(2):118-23.

15. Tveit OT, Seiler S, Halvorsen A, Rosland JH. Labour analgesia: a randomised, controlled trial comparing intravenous remifentanil and epidural analgesia with ropivacain and fentanyl. Eur J Anaesthesiol 2012;29(3):129-36. 